Bull. Egypt. Soc. Physiol. Sci. 34 (1), 121-135

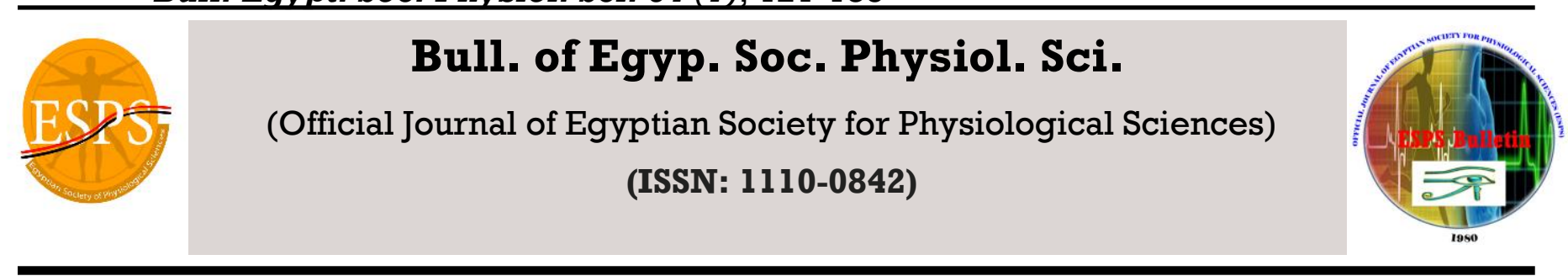

\title{
Role of Hemeoxygenase-1 on Ischemia Induced Preeclampsia-Like Syndrome in Rats
}

\author{
Nahid M. Tahoon ${ }^{1}$, Doaa H. Zineldeen ${ }^{2}$ and Karima El-Desuky3 \\ Departments of ${ }^{1}$ Medical Physiology, ${ }^{2}$ Medical Biochemistry and Molecular Biology and 3 \\ Pathology, Faculty of Medicine, Tanta University, El-Gharbia, Egypt
}

Received April 20, 2014

Accepted May 19, 2014

Available online July, 15,2014

\section{Keywords}

Hemeoxygenase-1

Ischemia

Placenta

Preeclampsia

\begin{abstract}
Background: Placental hypoxia/ischemia has been implicated as a central corn in the development of preeclampsia. One particularly useful model to study the impact of placental ischemia is the reduced uterine perfusion pressure model as it induces preeclampsia - like syndrome. Aim: This study aimed to demonstrate the effect of hemeoxygenase-1 on placental hypoperfusion in reduced uterine perfusion pressure model. Methods: The study was carried out on 50 timed pregnant female wistar rats divided into 5 equal groups; normal pregnant, reduced uterine perfusion pressure, reduced uterine perfusion pressure + Cobalt (III) Protoporphyrin IX Chloride, reduced uterine perfusion pressure + Cobalt (III) Protoporphyrin IX Chloride + tinprotoporphyrin IX and reduced uterine perfusion pressure + tin-protoporphyrin IX. In all these groups, number and weight of pups and maternal mean arterial blood pressure were measured. Then, blood, urine and placental samples were collected for measurement of microalbumin creatinine ratio, soluble fms-like tyrosine kinase, vascular endothelial growth factor, tumor necrosis factor- $\alpha$, super oxide dismutase and lactic dehydrogenase. Histopatholgoical examination of placentas of all groups was also done. Results and Conclusion: Reduced uterine perfusion pressure produced preeclampsia -like syndrome (hypertention, proteinuria and endothelial dysfunction). All biochemical parameters and histopathological pictures have been significantly improved by hemeoxygenase-1induction. So, hemeoxygenase-1 can be considered as a potential therapeutic target in the treatment of preeclampsia in the near future.
\end{abstract}

Corresponding author: Nahid M. Tahoon, Medical Physiology Department, Faculty of Medicine, Tanta University, Tanta, Egypt. E-mail: nahidtahoon@yahoo.com

Tel: 0405672617, Mobile: 01002677609 


\section{INTRODUCTION}

Preeclampsia (PE) is a unique human pregnancy disorder which contributes to up to $15 \%$ of preterm births and remains a leading cause of maternal and fetal morbidity and mortality worldwide. Hallmarks of the disorder are hypertension, proteinuria, and vascular dysfunction after 20 weeks of pregnancy ${ }^{(1)}$. Despite intensive research, the exact etiology of the disease is not well settled. However, a reduced placental perfusion due to failure of fetally derived trophoblast to adequately invade and remodel the maternal spiral arteries from high-resistance, low-capacity vessels to high-capacity, low-resistance vessels remains the most important one of the underlying origins of PE. Moreover, a key role of regulatory $\mathrm{T}$ - cells and natural killer cells in the orchestration of trophoblastic invasion at maternal-fetal interface has been suggested ${ }^{(2)}$. Others suggest the important roles of B- cell lymphoma/leukemia (Bcl-2) and hemeoxygenase-1 proteins in the antiangiogenic environment of $\mathrm{PE}^{(\mathbf{1})}$. There is also no specific effective pharmacological intervention for treatment of $\mathrm{PE}$ a part from preterm termination of pregnancy for maternal benefit, imposing the challenges of iatrogenic prematurity on the fetus ${ }^{(3)}$.

Two main pathways are implicated in the cascade from placental ischemia to maternal endothelial dysfunction. First, the production of reactive oxygen species (ROS). Second, the production of soluble form of vascular endothelial growth factor (VEGF) receptor-denominated as soluble fms-like tyrosine kinase (sFlt-1) which is an angiostatic factor. VEGF, which is a proangiogenic factor, is necessary for endothelial health and maintenance, when in circulation, sFlt-1 binds to free VEGF sequestrating it and making it unavailable for proper signaling (4). Endothelial dysfunction is characterized by impaired endothelium-dependant vasorelaxation and elevated expression of surface adhesion molecules resulting in increased leucocyte adhesion ${ }^{(5)}$.

Hemeoxygenase (HO) is an antioxidant antiinflammatory enzyme that catalyzes the breakdown of heme in the presence of $\mathrm{O}_{2}$ and reduced NADP (NADPH) to form carbon monoxide (CO), biliverdin, and iron. $\mathrm{CO}$ has been proposed to play a role in cellcell communication (neurotransmitter), relaxation of various blood vessels and inhibition of platelet aggregation. Biliverdin and its reduced form, bilirubin are potent antioxidants in several tissues. HO has three isoforms: HO-1 is the inducible isoform, HO-2 is the constitutive one and HO-3: is of unknown function ${ }^{(6)}$.

The principle aim of this study was to investigate the role of HO-1 induction in pregnant rat model of reduced uterine 
perfusion pressure (RUPP) to assess its role in PE.

\section{MATERIALS AND METHODS}

\section{Animals:}

Fifty timed pregnant female wistar rats were received on day 10 to 11 of gestation from animal house of Faculty of Science, Tanta University. All protocols were approved by the ethical committee of Tanta University. All rats were 14-15 weeks old and weighed 350- $450 \mathrm{gm}$. They were housed in animal cages at room temperature, on constant 12/12 hours light/dark cycle with free access to food and water. On gestation day (GD) 14 , forty rats underwent reduced uterine perfusion pressure (RUPP) procedure while 10 were sham-operated.

\section{RUPP procedure:}

On GP 14, animal was anaesthetized by controlled ether and a midline abdominal incision was made. After externalization of both uterine horns, constriction was made in lower abdominal aorta above the iliac bifurcation by $0.2 \mathrm{~mm}$ surgical clip. Two constrictions were also made on both right and left ovarian arteries by $0.1 \mathrm{~mm}$ surgical clips to prevent compensatory flow to uterus. The abdomen was then closed and animal allowed to recover. ${ }^{(7)}$.

HO-1 induction in vivo experimental protocol:
Five equal experimental groups were used to investigate the effect of $\mathrm{HO}-1$ induction in RUPP rat. All pharmacological interventions were administered for 5 days from GD1418.

I. Normal pregnant group (NP): Sham-operated, then received normal saline (vehicle) by IP injection from GD14- 18.

\section{RUPP group: RUPP was performed, then received vehicle by IP injection from GD 14- 18.}

III. $\quad$ RUPP + CoPP group: For HO-1 induction, Cobalt (III) Protoporphyrin IX Chloride (COPP; Frontier Scientific, Logan, UT) was IP injected $5 \mathrm{mg} / \mathrm{kg} /$ day) from GD14-18 ${ }^{(7)}$.

IV. $\quad R U P P+C o P P+S n P P$ group: to investigate whether any observed beneficial effects of CoPP was HO-1 depdendant, tinprotoporphyrin IX (Sn PP; a HO-1 inhibitor, Sigma Aldrich Co) was co administered orally in drinking water by gastric tube in a dose of $50 \mathrm{umol} / \mathrm{kg} / \mathrm{day}$ from GD14- $18^{(3)}$.

V. RUPP+ SnPP group: to examine the effects of HO-1 antagonism alone in RUPP rats, SnPP was administered orally as in group IV from GD14-18 ${ }^{(3)}$.

\section{Measurement of mean arterial blood pressure (MABP):}

On GD18, a chronic indwelling catheter was inserted into the carotid artery and on GD19; 
MABP was recorded in conscious animal by student lab apparatus ${ }^{(8)}$.

Urine analysis for microalbumin creatinine ratio (MCR):

On GD18, rats were singularly housed in separate cages for urine collection over night. MCR were calculated following measurement of albumin using an immunoturbidimetric test for quantitative determination of albumin on OLYMPUS analyzer and creatinine using kinetic color test for quantitative determination of creatinine in urine ${ }^{(9)}$.

On GD19: following urine collection and MABP record, rats were anaesthetized, ventral abdominal midline incision was reopened, the uterus was externalized and blood was collected by needle tapping of abdominal aorta. The number of viable pups was recorded in each uterus and weight of viable pups was also recorded. Samples of whole placentas were also weighed and stored in liquid nitrogen at $-80^{\circ} \mathrm{C}$ for further analysis and histopathological examination

\section{Histological analysis:}

Placentas were fixed in $4 \%$ formal buffered saline for 48 hours. Samples were processed, embedded in paraffin and $4 \mu \mathrm{m}$ sections were cut and subsequently stained with hematoxylin and eosin ( $\left.\begin{array}{lll}\mathrm{H} & \& & \mathrm{E}\end{array}\right)$. Morphometric measurement of intervillous distances was done in different views of placentas of each group (50 measurements per field) as an index of maternal perfusion (Leica Microscope, England) ${ }^{(10)}$.

For plasma preparation: whole blood was collected in precooled heparinised vacutainers. Blood was then centrifuged at $2400 \mathrm{~g}$ for $10 \mathrm{~min}$. The plasma is then removed and stored at $250 \mu \mathrm{L}$ aliquots at $80^{\circ} \mathrm{C}$.

For placental preparation: individual frozen placenta from same uterine horn was grouned in a mortar and pestle while submerged in liquid nitrogen. Resulting particles were resuspended and homogenized in radioimmunoassay buffer with a multiprotease inhibitor mixture. Homogenization was performed in glass tissue dounces and the solution was cleared by centrifugation to remove cellular debris. The resulting total protein was measured by the bicinchoninic acid method (Pierce Biotechnology) ${ }^{(11)}$.

Measurement of angiogenic mediators; soluble fms-like tyrosine kinase (sFlt-1) and vascular endothelial growth factor (VEGF): Circulating VEGF and placental sFlt-1 levels were measured in plasma and placental samples of all experimental groups using commercial sandwich ELISA kits available from R \& D system (Quantikine; sFlt-1 and VEGF) in duplicate according to manufacturer's protocols ${ }^{(5)}$. 
Tumor necrosis factor- $\alpha$ (TNF- $\alpha$ ): was estimated in plasma by Commercial Sandwich ELISA kits for rats according to the manufacturer's instructions (Biosource, International, Camarillo, California, USA) (12).

Superoxide dismutase (SOD): activity was measured in placental tissue using method of Sun et al., ${ }^{(13)}$.

Lactic dehydrogenase (LDH): as an indicator of cytotoxicity was estimated in plasma by enzymatic colorimetric methods (14).

\section{Statistical analysis:}

Data were expressed as mean \pm SD. Statistical difference involving multiple group comparisons were determined by one way analysis of variance (ANOVA) followed by the Tukey procedure for comparison of means. Statistical analysis was performed using GraphPad prism 5 software (GraphPad software, San Diego, USA). Correlations were analyzed using the Pearson test. Statistical significance was considered when $\mathrm{P}$-value was equal or less than 0.05 .

\section{RESULTS}

\section{As shown in tables (1 \& 2):}

RUPP procedure produced significant decrease in no. and weight of pups, VEGF, SOD and significant increase in MABP, MCR, sFlt-1, TNF- $\alpha$ and LDH when compared to normal pregnant group $(\mathrm{P}<$ $0.05)$.

HO-1 induction in RUPP model has significantly reversed all measured parameters except weight of pups which is insignificantly increased when compared to RUPP model $(\mathrm{P}<0.05)$.

Coadminstration of $\mathrm{HO}-1$ inducer (CoPP) and inhibitors (SnPP) produced significant decrease in no. of pups, VEGF, SOD and significant increase in MABP, sFlt- 1, TNF- $\alpha$ and LDH when compared to RUPP + CoPP $(\mathrm{P}<0.05)$.

However, HO-1 inhibitor (SnPP) alone in RUPP produced significant decrease in pup weight, SOD and significant increase in MCR, TNF- $\alpha$ and LDH when compared to RUPP + CoPP + SnPP $(\mathrm{P}<0.05)$. RUPP + SnPP also produced significant increase in MCR in comparison to RUPP group $(\mathrm{P}<$ 0.05). This group also showed significant decrease in no. of pups, VEGF and SOD and significant increase in MABP, MCR, sFlt1, TNF- $\alpha$ and LDH leakage when compared to RUPP + CoPP group $(\mathrm{P}<0.05)$.

\section{From table (3):}

sFlt-1 showed significant negative correlation with no. of pups and VEGF and significant positive correlation with MABP, MCR, TNF- $\alpha$ and LDH along all groups $(\mathrm{P}<$ $0.001)$.

Histopathological examination revealed 
that:

Placentas of NP rats showed normal villi with normal patent villous vessels and normally perfused intervillous spaces (Fig $1)$.

Placentas of all other groups which underwent RUPP model showed maternal hypoperfusion (indicated by decreased blood in intervillous spaces), with narrow intervillous spaces and perivillous fibrinoid deposits. Areas of hydropic degeneration and local infarcts were also seen in most cases (Fig 2).
There was significant improvement in the placentas of CoPP-treated group as the narrowing of intervillous spaces was mild, no degenerative or necrotic changes in villi (Fig 3).

There was significant worsening in the placentas of SnPP-treated groups either alone or with CoPP when compared with placentas of RUPP group as they showed inflammatory infiltrate, edematous villi and coagulative ischemic necrosis. Edematous membranes with focal ruptures were also noticed in some animals (Fig 4: A \& B and 5: A \& B).

Table (1): Mean, standard deviation and statistical significance of No. and weight of Pups, MABP, intervillous distances and MCR among studied groups

\begin{tabular}{|c|c|c|c|c|c|c|c|}
\hline Groups & I-NP & II-RUPP & $\begin{array}{l}\text { III-RUPP + } \\
\text { CoPP }\end{array}$ & $\begin{array}{c}\text { IV-RUPP+ } \\
\text { CoPP+ } \\
\text { SnPP }\end{array}$ & $\begin{array}{c}\text { V- RUPP + } \\
\text { Sn PP }\end{array}$ & $\mathbf{F}$ & $\begin{array}{c}\text { Relation } \\
(*)\end{array}$ \\
\hline $\begin{array}{l}\text { No. of Pups } \\
\text { (No.) }\end{array}$ & $10.1 \pm 2.28$ & $3.8 \pm 1.55$ & $7.2 \pm 1.32$ & $4.0 \pm 1.49$ & $3.1 \pm 1.20$ & 33.5 & $\begin{array}{l}\text { II vs I } \\
\text { III vs II } \\
\text { IV, V vsIII }\end{array}$ \\
\hline $\begin{array}{l}\text { Pup weight } \\
\text { (gm) }\end{array}$ & $3.38 \pm 0.95$ & $2.13 \pm 0.63$ & $3.08 \pm 0.74$ & $3.1 \pm 0.95$ & $1.93 \pm 0.52$ & 6.95 & $\begin{array}{l}\text { II vs I } \\
\text { V vs IV }\end{array}$ \\
\hline $\begin{array}{l}\text { MABP } \\
(\mathrm{mm} \mathrm{Hg})\end{array}$ & $90 \pm 6.15$ & $129 \pm 12.29$ & $93 \pm 5.57$ & $125 \pm 12.29$ & $134 \pm 12.29$ & 42.97 & \multirow{2}{*}{$\begin{array}{l}\text { II vs I } \\
\text { III vs II } \\
\text { IV,V vs III }\end{array}$} \\
\hline $\begin{array}{l}\text { Intervillous } \\
\text { distances ( } \mu \mathrm{m})\end{array}$ & $24.8 \pm 17.15$ & $7.6 \pm 10.04$ & $17.8 \pm 21.14$ & $6.1 \pm 4.14$ & $6.1 \pm 2.67$ & 20.57 & \\
\hline $\begin{array}{l}\text { MCR } \\
(\mathrm{mg} / \mathrm{mmol})\end{array}$ & $17.5 \pm 3.03$ & $59.4 \pm 6.67$ & $19.5 \pm 3.03$ & $22.5 \pm 3.03$ & $49.4 \pm 6.67$ & 160.6 & $\begin{array}{l}\text { II vs I } \\
\text { III vs II } \\
\text { V vs II,IV }\end{array}$ \\
\hline
\end{tabular}

(") significant $(P \leq 0.05)$ 
Table (2): Mean, standard deviation and statistical significance of sFlt-1, VEGF, TNF- $\alpha$, SOD and LDH among studied groups

\begin{tabular}{|c|c|c|c|c|c|c|c|}
\hline Group & I-NP & II-RUPP & $\begin{array}{l}\text { III-RUPP + } \\
\text { CoPP }\end{array}$ & $\begin{array}{c}\text { IV-RUPP + } \\
\text { CoPP+ SnPP }\end{array}$ & $\begin{array}{c}\text { V- RUPP + } \\
\text { Sn PP }\end{array}$ & $\mathbf{F}$ & Relation (*) \\
\hline $\begin{array}{l}\text { sFlt-1 } \\
\text { (pg/mg) }\end{array}$ & $\begin{array}{l}696.0 \pm \\
65.78\end{array}$ & $\begin{array}{c}1024.0 \pm \\
0.19\end{array}$ & $\begin{array}{l}729.0 \pm \\
74.27\end{array}$ & $1012.5 \pm 75.69$ & $\begin{array}{c}1004.0 \pm \\
70.19\end{array}$ & 53.82 & \multirow{2}{*}{$\begin{array}{c}\text { II vs I } \\
\text { III vs II } \\
\text { IV,V vs III }\end{array}$} \\
\hline $\begin{array}{l}\text { VEGF } \\
(\mathrm{Pg} / \mathrm{ml})\end{array}$ & $550 \pm 29.81$ & $343 \pm 33.02$ & $645 \pm 30.28$ & $302.0 \pm 26.58$ & $341.0 \pm 33.4$ & 244.57 & \\
\hline $\begin{array}{l}\text { TNF- } \alpha \\
(\mathrm{pg} / \mathrm{ml})\end{array}$ & $33.7 \pm 5.74$ & $104.5 \pm 9.32$ & $39.2 \pm 6.89$ & $81.0 \pm 9.76$ & $101.0 \pm 7.67$ & 175.73 & \multirow{3}{*}{$\begin{array}{c}\text { II vs I } \\
\text { III vs II } \\
\text { IV,V vs III } \\
\text { V vs IV }\end{array}$} \\
\hline $\begin{array}{l}\text { SOD (nmol } \\
/ \mathrm{min} / \mathrm{mg})\end{array}$ & $104.7 \pm 6.60$ & $87.1 \pm 5.13$ & $111.4 \pm 7.13$ & $92.1 \pm 5.13$ & $82.1 \pm 5.13$ & 43.17 & \\
\hline $\begin{array}{l}\text { LDH } \\
(\text { IU/L) }\end{array}$ & $60.8 \pm 6.88$ & $147.9 \pm 7.31$ & $79.6 \pm 6.45$ & $130.8 \pm 6.81$ & $151.8 \pm 7.05$ & 360.33 & \\
\hline
\end{tabular}

\section{(') significant $(P \leq 0.05)$}

Table (3): Correlation between sFlt-1 and some preeclampsia risk factors along all studied groups.

\begin{tabular}{|c|c|c|}
\hline & \multicolumn{2}{|c|}{ sFlt-1(pg/mg) } \\
\hline & r. & p. value \\
\hline \hline No. of Pups (No.) & -0.487 & $\mathbf{0 . 0 0 1} * *$ \\
\hline Pup weight $(\mathrm{gm})$ & -0.159 & 0.270 \\
\hline MABP(mmHg) & 0.581 & $\mathbf{0 . 0 0 1} * *$ \\
\hline MCR $(\mathrm{mg} / \mathrm{mmol})$ & 0.451 & $\mathbf{0 . 0 0 1} * *$ \\
\hline VEGF $(\mathrm{pg} / \mathrm{ml})$ & -0.499 & $\mathbf{0 . 0 0 1} * *$ \\
\hline TNF- $\boldsymbol{\alpha}(\mathrm{pg} / \mathrm{ml})$ & 0.590 & $\mathbf{0 . 0 0 1} * *$ \\
\hline SOD $(\mathrm{nmol} / \mathrm{min} / \mathrm{mg})$ & -0.239 & 0.095 \\
\hline LDH $(\mathrm{IU} / \mathrm{L})$ & 0.519 & $\mathbf{0 . 0 0 1} * *$ \\
\hline
\end{tabular}

\section{(") significant $(P \leq 0.05)$}

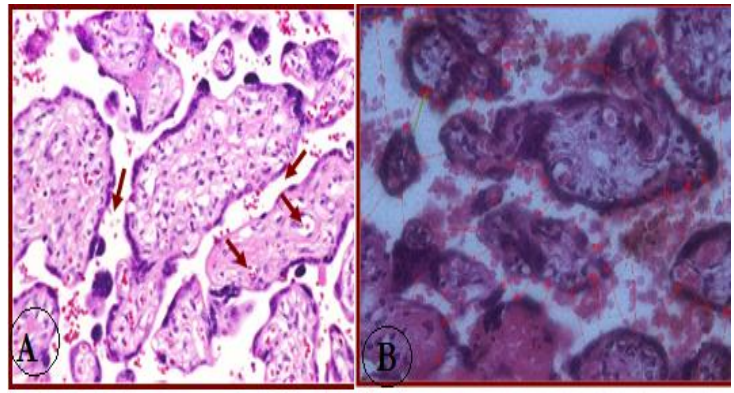

Fig. (1): A: H\& E staining of NP rat placenta showing: Normal villi with normal patent villous vessels and normally wide perfused intervillous spaces. B: Morphometry of intervillous distances $(H \& E \times 250)$.

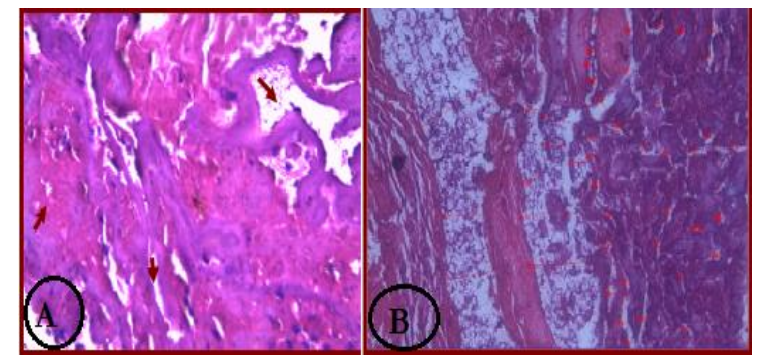

Fig. (2): A: H\&E staining of RUPP rat placentas showing: Maternal hypoperfusion, with very narrow intervillous spaces (villi are adherent to each other) with perivillous fibrinoid deposits. Degenerating villi with local infarcts. B: Morphometry of intervillous distances $(\mathrm{H} \& \mathrm{E} \times 250)$.

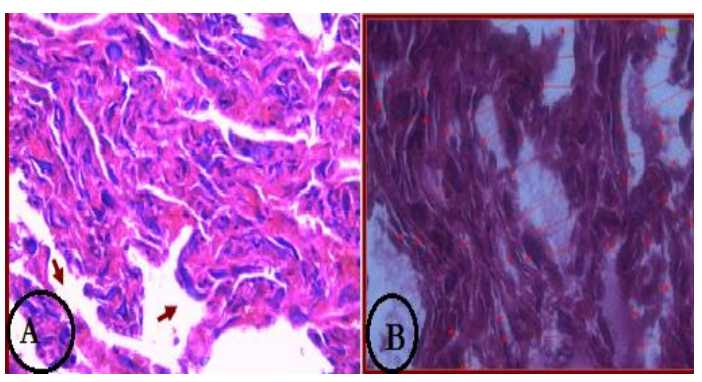

Fig. (3): A: H\&E staining of RUPP + CoPP rat placentas showing: Mild narrowing of intervillous spaces with obliterated fetal vascualrity. No degenerative or necrotic changes in villi. B: Morphometry of intervillous distances $(\mathrm{H} \& \mathrm{E} \times 250)$. 


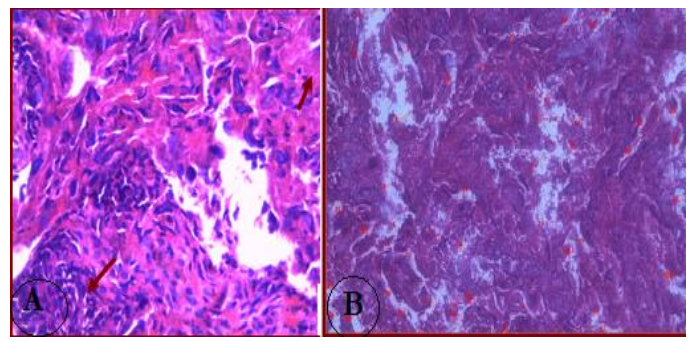

Fig.(4):A: H \& E staining of RUPP + CoPP + SnPP rat placentas showing: Hypercellular villi (inflammatory infiltration), narrow intervillous spaces with fibrinoid deposits, obliterated fetal vascularity and coagulative ischemic necrosis. B: Morphometry of intervillous distances (H\&E×250).

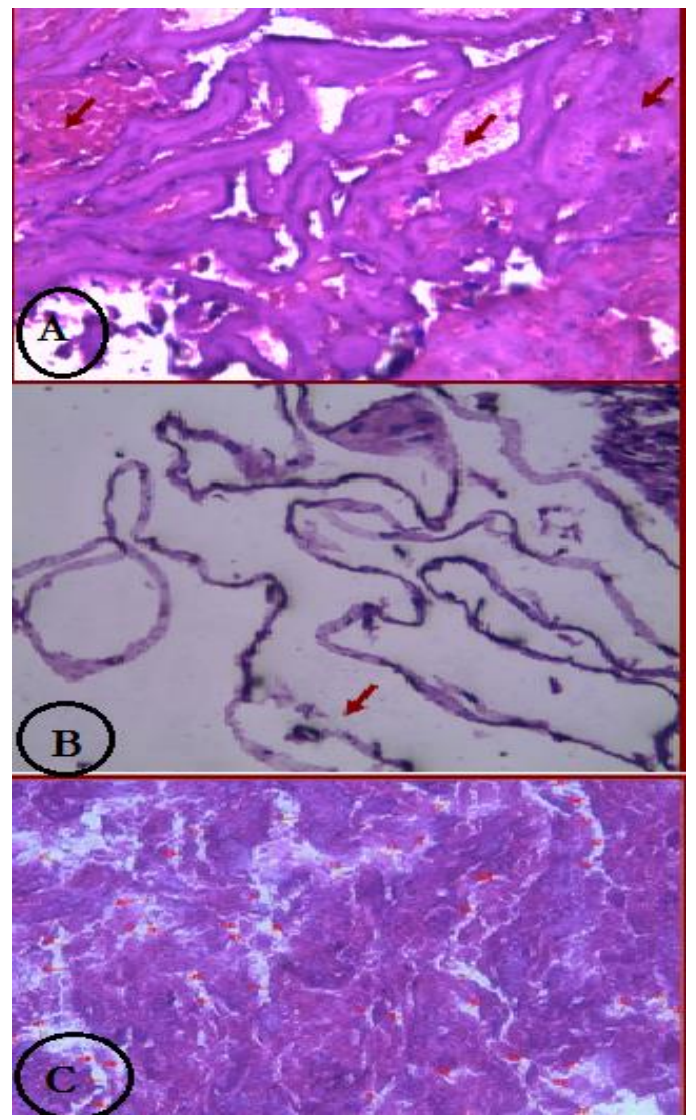

Fig.(5): A: H \& E staining of RUPP + SnPP rat placentas showing: Coagulative ischemic necrosis, villous oedema, narrow intervillous spaces with fibrinoid deposits and focal space congestion. B- Oedematous membranes with focal disruption and wide oedematous spaces. C: Morphometry of intervillous distances $(\mathrm{H} \& \mathrm{E} \times 250)$.

\section{Discussion:}

The precise etiology of PE is unclear, but lack of trphoblast mediated remodeling of spiral arterioles appears the most probable factor. Such that they are unable to accommodate the increase in blood flow demanded during late pregnancy and retain their ability to respond to vasoactive molecules ${ }^{(15)}$. Blood flow to placenta of preeclamptic women has been proposed to be intermittent or pulsatile. This may lead to regional hypoxia followed by reperfusion which in turn may result in oxidative damage and oxidative stress response genes as an adaptive response of hypoxic placenta. It is believed that placental infarcts (or areas of tissue damage) are caused by localized regions of hypoxia followed by reperfusion (16).

One experimental model has been proved to be useful for the study of PE in the (RUPP) model, in which mechanical constriction of the blood vessels feeding the uteroplacental unit leads to chronic ischemia and mimics many of the pathological features of the human disorder ${ }^{(\mathbf{1 7})}$.

In the present work, there is significant decrease in no. and weight of pups, VEGF, SOD and intervillous distances and significant increase in MABP, MCR, sFlt-1, TNF- $\alpha$ and LDH in RUPP group compared to normal pregnant group. These biochemical results were confirmed by 
histopathological findings which showed maternal hypoperfusion with very narrow intervillous spaces, degenerating villi with local infarcts and perivillous fibrinoid deposits.

The main consequences of hypoxia in RUPP model are oxidative stress and endothelial dysfunction which are hypothesized to be important mediators of inflammation and $\operatorname{apoptosis}^{(\mathbf{1 8})}$.

It is documented that elevated circulating levels of sFlt-1 are strongly correlated with $\mathrm{PE}$, appearing even before the clinical symptoms of the disorder and produced in response placental insufficiency ${ }^{(19)}$. Others demonstrated that introduction of exogenous sFlt-1in pregnant animals induces preeclampsia like syndrome ${ }^{(\mathbf{8})}$.

The increased angiostatic factor (sFlt-1) binds to the proangiogenic factor (VEGF) sequestrating it and preventing it from its proper function in maintaining endothelial health ${ }^{(5)}$. Kweider et al., stated that decreased VEGF and increased sFlt-1 lead to increased oxidative stress which contribute to vascular dysfunction in $\mathrm{PE}{ }^{\mathbf{( 2 0 )}}$. sFlt-1 together with soluble endoglins (sEng) are quite possible the final common pathway for hypertension and proteinuria and they can be reversed by VEGF administration to animal model ${ }^{(21)}$. Cudmore et al., found that administration of sFlt-1 or VEGF neutralizing antibodies results in glomerular endothelial dysfunction and proteinuria $^{(22)}$.

Oxidative stress due to release of reactive oxygen and nitrogen species (ROS \& RNS) is involved in hypertension and endothelial dysfunction, and that reduction of oxidative stress with SOD mimetic tempol or by NADPH oxidase inhibitor, apocynin led to significant decrease in maternal hypertension $^{(17)}$.

Chigusa et al., suggested that lectin like oxidized low density lipoprotein receptor 1 (LOX-1) is one of the scavenger receptors for oxidized LDL (oxLDL) and is abundantly expressed in normal placenta is decreased in preeclamptic placenta resulting in high oxLDL and low Nrf2 (nuclear factor erythroid 2- related factor 2) which is a master regulator of antioxidant and cytoprotective genes such as HO-1 ${ }^{(23)}$.

Inflammation follows oxidative stress. Zhao et al., suggested that increased peroxinitrite formation in maternal vasculature may contribute to cellular adhesion molecules and enhanced neutrophil endothelial interaction associated with PE ${ }^{(24)}$.

Hypertension in this model may also be caused by activation of endothelin type- A (ET-A) receptors by high sFlt-1 as administration of ET-A receptor antagonist abolished the associated effect ${ }^{(8)}$. Platelet activation/ aggregation also contribute to endothelial dysfunction and hypertension via 
proinflammatory and prooxidant pathways (11).

The treatment options for PE are extremely limited, namely, induction of labor and delivery of premature fetus that may carry risk of cardiovascular disease. This is sometimes the only way to solve the problem when symptomatic treatment fails to control the disease ${ }^{(3)}$. We have tried CoPP which has been shown to induce HO-1 expression at least partially through posttranscriptional manipulation of transcriptional repressor Bach 1 and stabilization of transcriptional factor $\mathrm{Nrf} 2$ is able to induce expression and activity of HO-1 both systemic and specifically in placenta of pregnant rat ${ }^{(25)}$.

CoPP treated RUPP succeeded to significantly improve all measured parameters when compared to RUPP group. This was confirmed by the improvement in histopathological examination which showed significant increase of intervillous distances and absence of degenerative or necrotic changes in villi.

Loss of HO-1 activity may be a causative factor in PE as it can suppress cytokinemediated release of sFlt-1 and soluble endoglin (sEng) ${ }^{(22,26)}$ and protect against TNF- $\alpha$ induced placental damage (27). Moreover, exposure to hypoxia $\left(1 \% \mathrm{O}_{2} ; \mathrm{Po}_{2}\right.$ $=16 \mathrm{mmHg}$ ) causes significant reduction in HO-1 expression and activity ${ }^{(22)}$.
Although hypoxia may increase HO-1 RNA and protein, there is progressive reduction in HO-1 activity with decreased oxygen concentration ( $\mathrm{CO}$ production is used as an index of HO-1 activity), and the dependence of HO-1 activity on oxygen concentration is similar in chorionic villi from non infracted areas of preeclamptic placenta and normal placenta (16). However Eide et al., documented that decidual expression and maternal serum levels of HO-1 are increased in $\mathrm{PE}^{(\mathbf{2 8 )}}$. Others stated that cells in placental villous tissue don't respond to hypoxia reoxygenation by altering amount of HO-1 or HO-2 protein ${ }^{(29)}$.

As regard the mechanistic role of $\mathrm{HO}-1$ induction in PE, the main mechanism is by decreasing sFlt-1 and increasing VEGF as; CoPP induction as well as its gaseous product $\mathrm{CO}$ significantly attenuated the hypoxia induced sFlt-1 release. Surprisingly, bilirubin alone significantly decreased sFlt-1 secretion in hypoxia but this was not as great as CoPP or $\mathrm{CO}$, suggesting that $\mathrm{CO}$ is the major factor in HO-1 effect on sFlt-1 and that oxidative stress is also playing a role in sFlt-1 induction (4,8). Cudmore et al., considered $\mathrm{HO} / \mathrm{CO}$ as a gate keeper preventing pregnancy induced oxidative stress and exacerbated inflammation by inhibiting release of antiangiogenic factors sFlt-1 and sEng ${ }^{(22)}$. 
Genetic over expression of HO-1 stimulates VEGF synthesis. It was found that HO-1 is involved in NO-dependant angiogenic events and $\mathrm{HO}-1$ is a mediator of $\mathrm{NO}$ induced VEGF synthesis in various cells and that NO donors enhanced VEGF expression in HO-1 dependant manner ${ }^{(30)}$.

A positive feedback loop was found between VEGF and HO-1 as the increased VEGF by HO-1 stimulates nuclear factors erythroid 2 related factor 2 (Nrf2) in an ERK 1/2dependant manner, Nrf2 is the main regulator of intracellular redox state stimulating antioxidant enzymes like HO-1. Increased $\mathrm{HO}-1$ leads to increased $\mathrm{CO}$ production which in turn increases VEGF expression through p38 kinase-dependant activation of $\mathrm{Sp} 1^{(20)}$.

The antihypertensive effect of CoPP in RUPP model involves multiple pathways like restoring sFlt-1/VEGF balance, cytoprotective effect through antioxidant effect of bilirubin ${ }^{(6)}, \mathrm{HO} / \mathrm{CO}$ pathway markedly attenuates the induction of preproendothelin (ET-1) to about half as $\mathrm{CO}$ negatively regulates its message in endothelial cells. Also VEGF might play a role in ET-1 suppression ${ }^{(\mathbf{8}, 31)}$. HO-1/CO pathway reduced ADP induced platelet aggregation in whole blood from RUPP, an effect that was blocked by SnPP ${ }^{(8)}$. HO-1 induction prevent TNF- $\alpha$ induced hypertension so it may be possible that anti- inflammatory effect of $\mathrm{HO}-1$ is a mechanism in $\mathrm{PE}{ }^{(27)}$. Lastly, HO-1/CO pathway inhibits hypoxia inducible factor-1 $\alpha$ (HIF-1 $\alpha$ ) induced sFlt-1 ${ }^{(4)}$.

The significant reduction in MCR by CoPP in RUPP may be due to its anti-inflammatory, antioxidant, antiapoptotic and cytoprotective properties $^{(\mathbf{1 1})}$.

Inhibition of $\mathrm{HO}-1$ production by $\mathrm{SnPP}$ either alone or with CoPP in RUPP produced insignificant changes when compared to each other and both produce significant worsening of all measured parameters when compared to CoPP treated RUPP group. This was confirmed by histopathological findings which showed no significant difference in between both groups but there is significant worsening in both groups when compared to CoPP treated RUPP group. This indicates that HO-1 plays an important role in $\mathrm{PE}$ and it is present in placenta of RUPP model.

\section{Conclusion:}

RUPP model induces PE-like disease. HO-1 and its metabolites may be considered as potential therapeutic target for PE treatment in the near future.

\section{References}

1. Varol F, Uzunoglu R, Erbas H, Sut N, Sayin C.: VEGFR-1, Bcl-2, and HO-1 Ratios in Pregnant Women with 
Hypertension, Clin Appl Thromb Hemost, 2013.

2. Robillard PY, Dekker G, Chaouat G.: Fourteen years of debate and workshops on the immunology of preeclampsia. Where are we now after the 2012 workshop? J Reprod Immunol, 2013.

\section{George EM, Hosick PA, Stec DE,} Granger JP.: Heme oxygenase inhibition increases blood pressure in pregnant rats. Am J Hypertens; 26 (7): 924- 30, 2013.

\section{George EM, Colson D, Dizon J, Palei} AC, Granger JP.: Heme Oxygenase-1 attenuates hypoxia-induced sFlt-1 and oxidative stress in placental villi through its metabolic products $\mathrm{CO}$ and bilirubin. Int J Hypertens; 2012: 486053, 2012.

5. Wu F.T.H, Stefanini M.O, Gabhann F.M, Kontos C.D, Annex B.H, Popel A.S.: A systems biology perspective on sVEGFR1: its biological function, pathogenic role and therapeutic use, Journal of Cellular and Molecular Medicine; 14 (3): 528- 552, 2010.

6. Levytska K, Kingdom J, Baczyk D, Drewlo S.: Heme oxygenase-1 in placental development and pathology, Placenta; 34(4): 291- 8, 2013.

\section{Granger JP, LaMarca BB, Cockrell K,} Sedeek M, Balzi C, Chandler D, Bennett W.: Reduced uterine perfusion pressure (RUPP) model for studying cardiovascular-renal dysfunciton in response to placental ischemia. Methods Mol Med; 122: 383- 392, 2006.

8. George EM, Arany M, Cockrell K, Storm MV, Stec DE, Granger JP.: Induction of heme oxygenase-1 attenuates sFlt-1- induced hypertension in pregnant rats, Am J Physiol Regul Integr Comp Physiol; 301(5): 1495- 500, 2011.

9. Mazzachi BC, Peake MJ, Ehrhard V.: Reference range and method comparison studies for enzymatic and Jaffe creatinine assays in plasma and serum and early morning urine. Clin. Lab: 53- 55, 2000.

10. Parast MM, Үи H. Ciric A. Salata MW, Davis V, Milstone DS.: PPAR $\gamma$ regulates trophoblast proliferation and promotes labyrinthine trilineage differentiation. PLoS One; 4: e8055, 2009.

11. McCarthy FP, Drewlo S, Kingdom J, Johns EJ, Walsh SK, Kenny LC.: Peroxisome proliferator-activated receptor- $\gamma$ as a potential therapeutic target in the treatment of preeclampsia, Hypertension; 58(2): 280-6, 2011.

12. Rajadura M.: Comparative effect of Aegle marmelos extract and alpha tocopherol on serum lipids, lipid peroxidation and cardiac enzyme in rats with isoproterenol-induced myocardial 
infarction. Sin. Med. J.; 46(2): 78-81, 2005.

13. Sun Y et al.: A simple method for clinical assay of superoxide dismutase. Clin Chem; 34: 497- 500, 1988.

14. King J.: The dehydrogenase or oxireductase lactate dehydrogenase in Practical clinical Enzymology (London): Van No Strand; 106, 1965.

15. Wong RJ, Zhao H, Stevenson DK.: A deficiency in haem oxygenase-1 induces foetal growth restriction by placental vasculature defects, Acta Paediatr; 101(8): 827- 34, 2012.

16. Lash GE, McLaughlin BE, MacDonald-Goodfellow SK, Smith GN, Brien JF, Marks GS, Nakatsu K, Graham CH.: Relationship between tissue damage and heme oxygenase expression in chorionic villi of term human placenta, Am J Physiol Heart Circ Physiol; 284 (1): 160-7, 2002.

17. George EM and Arany I.: Induction of heme oxygenase-1 shifts the balance from proinjury to prosurvival in the placentas of pregnant rats with reduced uterine perfusion pressure. Am J Physiol Regul Integr Comp Physiol; 302: 620-6, 2012.

18. Cindrova-Davies T. Preeclampsia: from placental oxidative stress to maternal endothelial dysfunction. Placenta 30; Suppl. A: S55-S65, 2009.

19. Rana S, Karumanchi SA, Levine RJ, Venkatesha S, Rauh-Hain JA,Tamez, Thadhani R.: Sequential changes in antiangiogenic factors in early pregnancy and risk of developing preeclampsia. Hypertention 50: 137-42, 2007.

20. Kweider N, Fragoulis A, Rosen C, Pecks U, Rath W, Pufe T, Wruck CJ.: Interplay between vascular endothelial growth factor (VEGF) and nuclear factor erythroid 2-related factor-2 (Nrf2): implications for preeclampsia, $J$ Biol Chem; 286 (50): 42863-72, 2011.

21. Ahmed A and Cudmore MJ: Can the biology of VEGF and haem oxygenases help solve pre-eclampsia? Biochem Soc Trans; 37 (6): 1237- 42, 2009.

22. Cudmore M, Ahmad S, Al-Ani B, Fujisawa T, Coxall H, Chudasama K, Devey IR, Wigmore SJ, Abbas A, Hewett PW, Ahmed A.: Negative regulation of soluble Flt-1 and soluble endoglin release by heme oxygenase-1, Circulation; 115 (13): 1789- 97, 2007.

23. Chigusa Y, Tatsumi K, Kondoh E, Fujita $\mathrm{K}$, Nishimura $\mathrm{F}$, Mogami $\mathrm{H}$, Konishi I.: Decreased lectin-like oxidized LDL receptor 1 (LOX-1) and low Nrf2 activation in placenta are involved in preeclampsia, $J$ Clin 
Endocrinol Metab; 97 (10): 1862- 7, 2012.

24. Zhao S, Zhang Y, Gu Y, Lewis DF, Wang Y.: Heme oxygenae-1 mediates up-regulation of adhesion molecule expression induced by peroxynitrite in endothelial cells, J Soc Gynecol Investig; 11 (7): 465-71, 2004.

\section{Shan $Y$, Lambrecht RW, Donohue} SE, Bonkovsky HL.: Role of Bach 1 and $\mathrm{Nrf} 2$ in up-regulation of the heme oxygenase-1 gene by cobalt protoporphyrin. FASEB J; 20: 2651- 3, 2006.

26. Cudmore MJ, Ahmad S, Sissaoui S, Ramma W, Ma B, Fujisawa T, Al-Ani B, Wang K, Cai M, Crispi E, Hewett PW, Gratacos E, Egginton S, Ahmed A.: Loss of Akt activity increases circulating soluble endoglin release in preeclampsia: identification of inter-dependency between Akt-1 and heme oxygenase-1, Eur Heart J; 33 (9): 1150-8, 2012.

27. Ahmed A, Rahman M, Zhang $X$, Acevedo CH, Nijjar S, Rushton I, Bussolati B, John ST.: Induction of placental heme oxygenase-1 is protective against TNF alpha-induced cytotoxicity and promotes vessel relaxation, Mol Med; 6 (5): 391- 409, 2000.
28. Eide IP, Isaksen CV, Salvesen KA, Langaas M, Schonberg SA, Austgulen R.: Decidual expression and maternal serum levels of heme oxygenase 1 are increased in pre-eclampsia, Acta Obstet Gynecol Scand; 87 (3): 272- 9, 2008.

29. McCaig $\boldsymbol{D}$ and Lyall $\boldsymbol{F} .:$ Heme oxygenase expression in human placental villous tissue in response to exposure to in vitro ischemiareperfusion injury, Hypertens Pregnancy; 28 (3): 256- 72, 2009.

30. Dulak J, Deshane J, Jozkowicz A, Agarwal A.: Heme oxygenase-1 and carbon monoxide in vascular pathobiology: focus on angiogenesis, Circulation; 117 (2): 231- 41, 2008.

31. George EM, Cockrell K, Aranay M, Csongradi E, Stec DE, Granger JP.: Induction of heme oxygenase 1 attenuates placental ischemia-induced hypertension, Hypertension; 57 (5): 941- 8, 2011. 


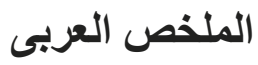

$$
\text { الهـف من البحث : }
$$

هو دراسة تأثير إنزيم الهيمأوكسجينيز ـ ا على نموذج نقص ضغط التدفق الدموى للرحم. هذا النموذج يشبه ما يحدث فى قبل تسمم الحمل.

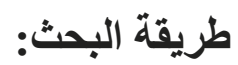

أجرى البحث على خمسون فأراً فى اليوم ع ا _ 1 1 من الحمل قسمت بالتساوى إلى خمس

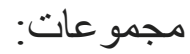

\section{مجمو عة طبيعية ضابطة.}

مجمو عة نقص ضغط التدفق الدموى للرحم.

مجموعة نقص ضغط التدفق الدموى + المادة المعطية لإنزيم الهيمأوكسجينيز - . مجمو عة نقص ضغط التدفق الدموى + المادة المعطية لإنزيم الهيمأوكسجينيز - 1 + المادة

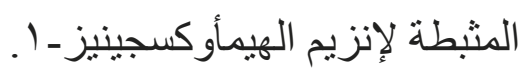

مجمو عة نقص ضغط التدفق الدموى + المادة المثبطة لإنزيم الهيمأوكسجينيز - . . فى كل المجموعات تم قياس عدد ووزن الفئران المولودة وضغط الدم المتوسط لأمهات

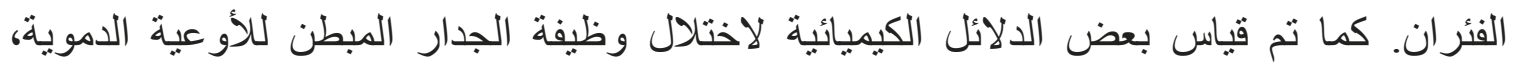

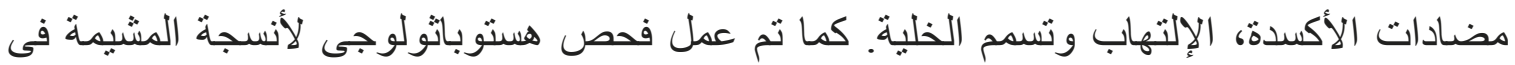

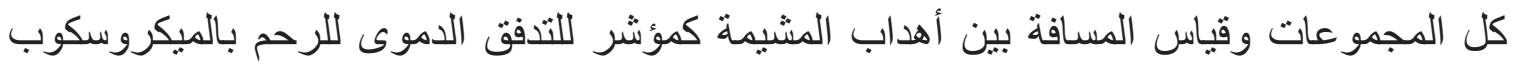

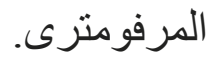
النتائج والإستنتاج:

نموذج نقص ضغط التدفق الدموى للرحم يشبه ما قبل تسمم الحمل ـ إنزيم الهيمأوكسجينيز تسبب فى تحسن جميع الدلائل الكيميائية والصورة الهستوباثولوجية الناتجة عن نقص ضغنط التدفق الدموى. لذلك من الممكن أن يكون علاجاً لقبل تسمم الحمل فى المستقبل القريب. 